\title{
O PAPEL DO FALCÃO NA "NOVELA DO FALCÃO" DE G.BOCCACCIO*
}

\author{
Valéria Andrade Souto-Maior
}

Doutoranda em Literatura Brasileira - UFPB

* Texto apresentado originalmente como trabalho final do curso "A Novela, de Boccaccio a Kafka", ministrado pelo Prof. Dr. Modesto Carone Netto, no Curso de Pós-Graduação em Letras/Doutorado em Literatura Brasileira da UFPB, em abril de 1996.

Resumo

O presente texto aponta para a presença de um elemento que, na novela - definida teoricamente como gênero narrativo dotado de estrutura dramática - cumpre a tarefa de conduzir o conflito central ao seu ponto máximo. Designado como turning point, esse ponto - que marca o parentesco entre a novela e 0 drama - configura 0 momento em que o conflito transforma-se subitamente na sua própria resolução.

Mais curta que o romance, mais longa que o conto - assim poderia ser resumida a 'receita' básica habitualmente encontrada nos manuais de 'culinária acadêmica' para se definir/caracterizar a novela. Seguramente correta, a definição que situa esta forma narrativa como intermediária, em extensão, ao romance e ao conto, não se mostra, contudo, desenvolvida o suficiente para evidenciar alguns do seus traços característicos mais marcantes, que, de certo modo, paradoxalmente, permitem identificar uma espécie de parentesco entre a novela e o drama, aqui entendido como designação do gênero dramático em geral.

Decorrente do privilégio que, na construção de uma novela genuína, é concedido à ação e à concentração da mesma em determinadas situações de crise, uma das principais características dessa forma narrativa vem a ser a presença de um conflito central, que é precisamente um dos elementos básicos e determinantes da ação dramática. Inerente, assim, também à novela, esse conflito - tal como no drama, nascido da tensão e do entrechoque de vontades dos personagens - cresce e se multiplica em vários outros conflitos, que vão se encadeando entre si e se exacerbando, num crescendo acelerado, até atingirem umlimite máximo, a partir do qual, precipitadamente, tudo se resolve.

Empurrando, portanto, ininterrupta e rapidamente, o enredo para o seu final, o conflito presente na novela - anunciado logo em seu início e aumentado até o extremo por conflitos menores e a ele interligados - sofre em seu ponto de saturação uma variação qualitativa, transformando-se inesperadamente, a partir de um determinado acontecimento, na sua própria resolução. A presença desse acontecimento, que muda o curso da narrativa, fazendo-a precipitar-se irremediavelmente em direção ao desfecho, é outro traço que, sem dúvida, determina de modo mais marcante o caráter da novela. Designado como turning point, esse momento crucial da narrativa - sem o qual uma novela não se efetiva como tal - é, em outras palavras, aquele ponto em que o clímax torna-se praticamente também o próprio desenlace, registrando-se assim uma coincidência quase total entre esses dois momentos do enredo. 
Vale ressaltar que tal coincidência, entretanto, não advém da condensação que sendo própria do conto, devido a sua extrema parcimônia com relação aos elementos estruturadores de uma narrativa, determina a apresentação de situações que aparecem antes como um instantâneo da vida de seus personagens. A esse respeito, cabe ainda observar que, no caso da novela, as situações são apresentadas dentro de fronteiras um pouco mais amplas, mas não tanto quanto as apropriadas ao romance. Além disso, as situações próprias à novela tratam dos problemas fundamentais da vida, sendo esse, aliás, um outro aspecto que contribui para que ela seja encarada como gênero aparentado com o drama.

Feitas estas considerações mais gerais sobre o perfil característico da novela, minha intenção aqui é de fazer um rápido exame em torno do papel que, na 'novela do falcão', de G. Boccaccio, é desempenhado exatamente pelo falcão. A partir daí, talvez não seja despropositado considerar a possibilidade de apontar essa narrativa como um exemplar típico do gênero em questão.

Incluída como nona novela de uma das dez jornadas que compõem a moldura delineada por Boccaccio em seu Decamerão - mais precisamente, a quinta jornada, na qual são relatados casos de amor felizes acontecidos depois de episódios difíceis e desafortunados - a 'novela do falcão' narra a história de Frederico, rapaz rico e bem-educado, que tendo se apaixonado por uma nobre senhora, tão bela quanto honesta, chamada Joana, gasta toda a sua fortuna em festas, torneios de armas e presentes, na tentativa vã de conquistar-lhe o coração. Restando-lhe, como únicos bens, um extraordinário falcão e uma pequena propriedade rural, Frederico para lá se transfere, onde passa a sobreviver auxiliado por sua ave de rapina. Mãe de um garoto já crescido, Joana ficara viúva e, seguindo os hábitos locais, fora passar o verão no campo, onde possuía um sítio bem próximo àquele de Frederico. Encantado com o falcão do vizinho, o filho de Joana ficou ardentemente desejoso de tê-lo como seu. Porém, ciente do valor que o mesmo tinha para o seu dono, o menino jamais ousou manifestar-lhe tal desejo.

Um dia, gravemente adoentado e instigado pela mãe a pedir o que desejasse, para, quem sabe, assim, ao ser atendido, sentir-se mais animado e curar-se logo, o menino confessou o desejo que nutria pelo falcão de Frederico. Joana, apesar de transtornada com semelhante pedido mas, ao mesmo tempo, convicta de que seu antigo apaixonado lhe daria a valiosa ave, embora ela, de sua parte, jamais tivesse lhe dado qualquer sinal de esperança - prometeu ao filho que ele teria o falcão.

Simulando uma visita de cortesia, Joana dirigiu-se à casa de Frederico e, manifestando-Ihe sua intenção de compensá-lo pelos danos que ela lhe causara no passado, disse-lhe que, por essa razão, viera Ihe visitar e almoçar em sua companhia. Angustiado diante da tardia percepção de que, de fato, nada possuía em sua casa que pudesse oferecer em honra de tão nobre visita, depois de ter-se comportado como se estivesse fora de si, Frederico pousou os olhos, subitamente, em seu precioso falcão. Convencido de que a ave era a sua salvação, o rapaz torceu-lhe o pescoço, sem qualquer hesitação e, em pouco tempo, já anunciava que a mesa do almoço estava posta.

Ignorando completamente que Frederico havia Ihe servido o falcão como refeição, Joana passou a explicar-lhe, logo após o almoço, o real motivo da sua visita. Antes de encontrar palavras para responder ao que a mulher lhe pedia, e sem se importar com a presença dela, Frederico pôs-se a chorar. Quando o choro cessou, ele lamentou-se pesarosamente sobre sua terrível sorte, a qual, naquele momento, tornava absolutamente impossível que ele a atendesse. 
E revelou-lhe a razão do desespero em que ele, a partir de então, passaria a viver: a ave, que ela queria viva, ele a havia servido assada, como a mais preciosa refeição que ele pudera preparar em honra de sua visita.

A grandeza de alma de Frederico assim revelada a Joana, causou-lhe forte e profunda impressão, de tal sorte que mais tarde, já passada a sua amargura pela perda do filho, morto em poucos dias, a nobre mulher, aceitando os conselhos fraternos, resolveu casar-se novamente, desde que seu novo marido viesse a ser Frederico. Ela, que por determinação do falecido esposo, passara a ser, após a morte do filho, a sua única herdeira, tornou-se uma

mulher riquíssima e, casando-se com Frederico, fez dele um homem também riquíssimo e realizado no amor.

Mostrando por inteiro o amor cortês em sua elegância típica, esse enredo, construído sem maiores complicações, deixa claro também, logo de início, que esse amor é, em sua própria origem, a base de um grande conflito que aí se arma. Contrapondo a paixão de um cavalheiro por uma dama à indiferença dela por esse amor, esse conflito - nascido da oposição entre essas duas vontades, a de amar e a de não amar - se instala no centro da narrativa como fonte que tanto irradia quanto centraliza outros conflitos. E estendendo-se ao longo de toda a novela, esse conflito principal vai se tornando mais avultado à medida que conflitos periféricos, não exatamente secundários, vão sendo deflagrados como uma espécie de produtos de sua 'automultiplicação'.

Dessa forma é que Joana - na tentativa de animar o filho doente, dando-lhe algo que ele muito desejava, o falcão de Frederico - se vê torturada pela dúvida de pedir, ou não, ao homem por ela desprezado, o único bem que ele preservara após dissipar sua riqueza no afã de conquistá-la. Contudo, incomparavelmente mais forte que o constrangimento a que ela se veria exposta nessa circunstância, seu amor de mãe a faz tomar a decisão de ir pessoalmente, pedir o falcão a Frederico. Este, por sua vez, na ignorância do verdadeiro motivo da visita que recebia e frente à angustiante situação de querer e não ter em casa um alimento digno com o qual ele pudesse honrar essa visita, corre de um lado para outro, desesperado, até que, pondo os olhos em seu falcão, se convence de que o seu precioso animal era, de fato, tudo o que ele precisava, e tinha, para preparar uma refeição à altura da homenagem que desejava prestar.

Seguindo em sua trajetória ascendente, o conflito originalmente instalado na novela cresce um pouco mais a partir do momento em que o falcão de Frederico, servido à mesa como manjar festivo, passa a ser de Joana, sem que ela o soubesse e, portanto, antes mesmo que o tivesse pedido. E não apenas, esse conflito torna-se ainda maior quando, após o almoço, Joana pede a Frederico que lhe dê o falcão, na mais completa ignorância de que ela já o

possuía em seu próprio estômago.

A resposta negativa de Frederico, dada juntamente com a explicação da sua razão de ser, provoca a exacerbação da crise que então vinha se desenvolvendo entre os dois protagonistas. Atingindo aí o seu ápice, aquele conflito inicial sofre uma transformação repentina e definitiva, fazendo a narrativa tomar outro rumo e ser levada, precipitadamente, para o seu final. Em outras palavras, a partir desse ponto da narrativa - que não é outro senão o já mencionado turning point - o que ocorre é uma corrida desenfreada em direção à conclusão da história, uma vez que a mudança por ele efetuada implica na própria resolução de todos os conflitos, inclusive, é claro, do principal, pois Joana, encantada com a nobreza de caráter revelada pelo gesto de 
Frederico, muda de idéia completamente e decide casar-se com ele. Tendo herdado, após a morte do filho, toda a imensa riqueza do seu falecido marido, Joana promove, com esse casamento, tanto a realização do amor que Frederico sempre tivera por ela, como também a devolução da fortuna que ele perdera no passado, em suas tentativas de ter esse amor.

Autenticada, portanto, pela presença tanto do turning point como do conflito central, a 'novela do falcão' traz seu perfil marcado intensamente por esses dois traços, de modo a fazer imaginar que, ao escrevê-la, seu autor tinha o mais firme propósito de produzir uma amostra significativa do gênero narrativo que se convencionou chamar novela.

E mais ainda, isso permite supor também que, na execução desse seu propósito, ele teria verificado a necessidade de incluir nesse tipo de narrativa um elemento que se incumbisse da tarefa decisiva de levar o conflito central a desembocar no turning point. E no caso específico dessa sua novela, esse papel foi entregue ao falcão. É esse personagem que faz com que o conflito central, inicialmente fluido e esparso, vá se condensando até que, num determinado ponto, passa a ter uma forma sólida, quando então se converte numa espécie de cristal, cuja transparência torna perfeitamente possível que através dele se enxergue e se reconheça a sua própria essência.

Não parece ser diferente disso o que se configura no momento em que Frederico nega a Joana o presente que ela pedira, pois se ele o faz, é ainda, e paradoxalmente, devido ao imenso amor que tem por ela. Mostrado a princípio como único bem restante da riqueza de Frederico, perdida por amor a Joana, o falcão passa a ser, consecutivamente, objeto de desejo dela e tábua de salvação dele. Quando, finalmente, é apresentado a ambos como último bem daquela mesma riqueza, perdido por aquela mesma razão, o falcão passa a ser a própria crise, da qual, até ali, ele fora unicamente o condutor. E não apenas, de ponto crítico o falcão se transforma, nesse exato momento, na própria resolução do conflito central, pois quando Joana toma conhecimento do fim que ele levara, o jogo vira e ela resolve casar-se com Frederico. A um só tempo agente da discórdia e da paz, o falcão talvez até merecesse o cognome de Pom(b)o, que em sua (confusão, aqui deliberadamente

proposta, denuncia a ambigüidade do papel por ele desempenhado na narrativa.

Como última observação, devo ainda chamar a atenção para o parentesco entre a novela e o drama, já antes visto como possível de ser identificado com relação tanto à presença desses dois traços aqui examinados, quanto da discussão de problemas fundamentais vividos pelo ser humano. No entanto, a 'novela do falcão' parece indicar a existência de um outro ponto que, sem dúvida, contribui para enfatizar a referida afinidade entre os dois gêneros. Neste sentido, importa notar que, a exemplo daquilo que se busca no drama em geral e, particularmente, na tragédia, o desenlace dessa novela estabelece uma vitória definitiva - a do amor de Frederico por Joana - seguida de uma pacificação, que aparece explicitada, com todas as letras, em seu último parágrafo:

"Frederico, vendo-se casado com tão bela mulher, que tanto havia amado, e tornando-se, além disso, riquíssimo, longos anos viveu em harmonia e encantamento com ela; tornou-se melhor homem de família; e suavemente, em companhia dela, concluiu seus anos." 
